\title{
An Examination Of Organizational Citizenship Behavior In An Academic Setting From The Perspective Of The Five Factor Model
}

\author{
Willard G. Broucek, Ph.D., (E-mail: broucekw@ northern.edu), Northern State University
}

\begin{abstract}
This paper examines the dispositional causes of student organizational citizenship behavior $(O C B)$ in an academic setting by utilizing facets scales of the NEO-PI-R (Costa \& McCrae, 1992) in addition to the five broad dimensions of the five factor model of personality. Different facet scales were significantly related to organizational citizenship and to student satisfaction. The strongest predictor of $O C B$ was found to be warmth, a facet of extraversion. This finding supported the contention of Lepine, et al. (2002) that OCB can best be conceptualized as a latent construct measuring cooperativeness.
\end{abstract}

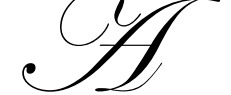

s organizations complete the paradigm shift from formal hierarchical structures and individualized jobs to team-based work structures (Ilgen \& Pulakos, 1999) organizational citizenship behavior (OCB), or behavior that contributes indirectly to the organization through maintenance of the organization's social system (Organ, 1997), has become of increasing interest to academics and practitioners alike (Lepine, Erez \& Johnson, 2002; Podsakoff, Mackenzie, Paine, \& Bachrach, 2000; Motowildo \& Schmidt, 1999, Organ \& Ryan, 1995).

Organ (1977) and his colleagues (Bateman \& Organ, 1983; Smith, Organ, and Near, 1983) first used the term organizational citizenship behavior to describe work behavior that is discretionary, not directly or explicitly recognized by the formal reward system, and that, in the aggregate, promotes the effective functioning of the organization (Organ, 1988, p.4). Other terms for overlapping behavioral domains include prosocial organizational behavior (Brief \& Motowildo, 1986), organizational spontaneity (George \& Jones, 1997), and extrarole behavior (Van Dyne, Cummings, \& McLean Parks, 1995). Contextual performance (Borman \& Motowildo, 1993, 1997), activities that support the social and psychological context in which the organization's technical core is embedded, similarly overlaps with OCB though the latter has historically emphasized discretionary behavior that was not formally rewarded while the former does not. Organ recently redefined OCB as behavior that contributes "to the maintenance and enhancement of the social and psychological context that supports task performance" (Organ 1997, p.91) thus bringing the two concepts much closer together.

Numerous taxonomies of OCB-like behaviors have been proposed and operationalized. Smith et al. (1983) conducted structured interviews of managers who identified instances of helpful subordinate behavior that were not absolutely required job behaviors. Factor analysis of ratings of subordinates on these behaviors revealed two factors. Altruism, the first factor, referred to behavior directly intended to help a co-worker in a face-to-face situation (e.g., helping others who have been absent, volunteering for things that are not required). Generalized compliance, the second factor, referred to impersonal behaviors (being punctual, not taking undeserved breaks).

Organ (1988) expanded the taxonomy to 5 types of behaviors. He narrowed the definitions of altruism and

Readers with comments or questions are encouraged to contact the author via email. 
compliance (as well, re-naming the latter conscientiousness); and added sportsmanship (e.g., not complaining about trivial matters), courtesy (e.g., consulting with others before taking action), and civic virtue (e.g., keeping up with matters that affect the organization). Podsakoff, Mackenzie, Moorman, \& Fetter (1990) operationalized these dimensions. Though this measure has frequently been used its use by no means universal.

Examples of other taxonomies include Borman and Motowildo (1993); VanDyne, Graham, \& Dienesch (1994); Morrison (1994); Van Scotter and Motowildo (1996); and Coleman and Borman (2000). The behavioral domains of these taxonomies overlap with one another and with Organ's (1988) OCB domain to varying degrees. For example, Morrison's (1994) altruism dimension overlaps with Organ's (1988) altruism and courtesy. Her involvement dimension overlaps with Organ's sportsmanship and civic virtue while her 'keeping up with changes' dimension overlaps with civic virtue and conscientiousness.

Coleman and Borman (2000) examined the extent to which the proliferation of behavioral elements that fit the varying operational definitions of OCB represent a broader underlying construct or constructs. Using similarity data generated through content sorting of 27 citizenship behaviors and factor analysis, multidimensional scaling, and cluster analysis they found categories of behavior that vary with respect to the behaviors' beneficiary, i.e., one set of behaviors benefited other organizational members while a second benefited the organization. The former, labeled the interpersonal citizenship performance dimension, included Organ's (1988) altruism and courtesy dimensions while the latter, labeled the organizational citizenship performance dimension, included Organ's (1988) sportsmanship, civic virtue, and conscientiousness dimensions. These findings were supportive of Williams and Anderson (1991) who posited that organizational citizenship behavior directed toward individuals (OCBI) is distinct from organizational citizenship behavior directed toward the organization (OCBO).

Lepine et al. (2002), noting the ambiguity concerning both the definition of OCB and its measurement, conducted a meta-analysis designed to determine if OCB should best be conceptualized as a latent construct whose dimensions were all imperfect indicators of the same underlying construct or as an aggregate construct in which each dimension was a distinct, summative part of the OCB construct. For example, Motowildo (2000) distinguished contextual performance as a clear example of an aggregate multidimensional construct, i.e., the aggregated value to the organization of all the behavioral episodes that have effects on the social, organizational, and psychological context of the organization's technical core; as opposed to OCB which he suggested was similar to a latent personality construct that caused the behaviors reflected in its dimensions.

Using Hierarchical Linear Modeling (HLM) and random effects meta analysis Lepine et al. (2002) found results "...consistent with the notion that the five dimensions of OCB are not much more than equivalent indicators of OCB" (Lepine et al., 2002, pp. 60-61). Further, the study characterized the five dimensions as all being behavioral manifestations of positive cooperativeness at work.

Given Lepine et al.'s (2002) findings it is curious that the dispositional variable of agreeableness which includes cooperativeness and positive interpersonal relationships has not frequently been shown to be related to OCB as one would expect given the above characterization. In fact, only Neuman and Kickul (1998) have reported finding a significant relationship between agreeableness as defined by the Five Factor Model (Costa and McCrae, 1991) and OCB in a retail sales environment.

More typically, no dispositional variable other than conscientiousness (Podsakoff et al., 2000) has been shown to be related to OCB's. Organ and Lingl (1995) found that conscientiousness, but not agreeableness, was significantly related to OCB in manufacturing settings in the US and UK. Neuman and Kickul (1998) found that both conscientiousness and agreeableness were related to OCB in the study cited previously.

It is important to recognize, however, that only a limited set of dispositions have been examined in the literature (Organ \& Ryan, 1995). Neuman and Kickul (1998) used the NEO PI-R (Costa and McCrae, 1989), widely regarded to be the most comprehensive measure of the Big Five but they only utilized the extraversion, agreeableness, and conscientiousness domain scales and omitted the neuroticism and openness domains. Organ and Lingle (1995) used a similar Big Five measure, McCrae and Costa's (1987) forced-choice adjective-pair format 
measure of agreeableness and conscientiousness but again did not examine the other three dimensions. Further, no study has examined the relationship between OCB and the narrow facets or traits of personality that comprise the five broad dimensions. Paunonen and Ashton (2001) have demonstrated that this more detailed approach to personality assessment can substantially increase the maximum prediction achieved by the broad factors.

The goal of this study was two-fold. The first was to systematically examine the relationship between OCB and personality by utilizing both a comprehensive measure of all five factors and a detailed measure of the narrower personality facets that make up the five broad dimensions. The second goal was to extend the application of OCB from the myriad number of work-type settings used to the academic setting.

In terms of the first goal, it is argued that use of all 5 broad dimensions as well as their facet scales is the most definitive means of examining the relationship between personality and OCB. Specifically, it is hypothesized on the general level that the dimensions of conscientiousness and agreeableness will be positively related to OCB. Such a result will essentially replicate the findings of Neuman and Kickul (1998). As well, it is hypothesized that the agreeableness facets of altruism and compliance and the conscientiousness facets of dutifulness and achievement striving will be directly related to OCB.

According to the NEO-PI-R manual (Costa and McCrae, 1992) altruism defines an active concern for others as shown in generosity, consideration, and a willingness to assist others in need of help. Compliance, on the other hand, refers to deference to others in conflict situations and the preference for cooperation over competition. In terms of the conscientiousness facets, dutifulness is defined as adherence to an ethical code and scrupulous fulfillment of moral obligations while achievement striving is defined as having high aspiration levels and working hard to obtain goals.

Further it is noted that one facet of Extraversion comes quite close to LePine et al's. (2002) characterization of OCB as positive cooperativeness at work. Warmth is defined as the "...facet of extraversion that is closest to agreeableness in interpersonal space, but it is distinguished by a cordiality and heartiness that is not part of A." (Costa and McCrae, 1992, p.17). Warm people are said to be affectionate and friendly and to genuinely like other people. It thus is likely that this facet may emerge as also being related to OCB.

In addition it is assumed that use of a comprehensive measure of the Big Five and its discrete facets will help to address the question of the relationship between OCB, Job Satisfaction, and personality. If personality traits are the underlying explanation of the correlation between OCB and Job Satisfaction then they should both be related to the same causal trait. To the extent that personality traits, OCB, and Job Satisfaction are correlationally distinct will address the dependence-independence relationship between the three.

Finally, in terms of the second goal, OCB has been a construct that has only been applied in the workplace. The academic setting, however, has many parallels to the workplace. It should be possible to extend the concept to university performance. It can be argued that to the extent that students engage in OCB in class that they increase the likelihood of student retention.

\section{Method}

Participants

Business students at a small public university participated in the study for extra credit. One hundred and sixteen students, 65 female, 51 male, average age 24.4 years, completed self-report measures of interest.

\section{Procedure}

Students were given packets of questionnaires which they returned over a two week period three quarters into the semester. Participation was voluntary. 
Measures

The personality test administered was the NEO-PI-R (Costa \& McCrae, 1989). The NEO-PI-R measures five major dimensions of personality allowing a comprehensive assessment of normal personality. The domain scales are neuroticism, extraversion, and openness to experience, agreeableness, and conscientiousness. In addition each domain is comprised of six facet scales. Cronbach's alphas for the domain scales were: $\mathrm{N}(.91), \mathrm{E}(.89), \mathrm{O}(.88)$, $\mathrm{A}(.86)$, and $\mathrm{C}(.90)$.

OCB was measured with a 21 item scale adapted to the university classroom setting. Examples of items are: "I lend my notes to classmates who have missed a class", " I speak well of my teachers", and "I complete the necessary readings, exercises before each class". Students responded to the items on a 5 point Likert scale ranging from strongly agree to strongly disagree.

Student satisfaction was measured with a six item student satisfaction scale developed for the study. A sample item is: "I feel satisfied being a student". Students responded to the items on a 5 point Likert scale ranging from strongly agree to strongly disagree.

\section{Results}

Descriptive statistics and intercorrelations for the variables in the study are presented in Table 1 . In examining the first hypothesis, only conscientiousness was significantly correlated with OCB. Also, contrary to prediction, while agreeableness was not significantly correlated to $\mathrm{OCB}$, extraversion and openness were.

\section{Table 1}

Correlation Matrix

\begin{tabular}{|c|c|c|c|c|c|c|}
\hline & 1 & 2 & 3 & 4 & 5 & 6 \\
\hline 1. Ocb & -- & & & & & \\
\hline 2. Neuroticism & -02 & -- & & & & \\
\hline 3. Extraversion & $22 *$ & -12 & -- & & & \\
\hline 4. Openness & $22 *$ & -08 & 15 & -- & & \\
\hline 5. Agreeableness & 17 & -18 & 10 & 17 & -- & \\
\hline 6. Conscientiousness & $22 *$ & 02 & -06 & $22 *$ & -19 & \\
\hline 7. Satisfaction & $62 * *$ & -18 & 13 & $35 * *$ & 01 & $23^{*}$ \\
\hline
\end{tabular}

Also in Table 1 it is evident that OCB is significantly associated with both measures of student satisfaction. As well both satisfaction measures are significantly correlated with both conscientiousness and openness to experience.

Regression analysis was conducted to examine the relationship between OCB, satisfaction, the Big Five, and their facets. Table 2 presents the results of the analysis for OCB. 
Table 2

Multiple Regression Analysis Of Ocb \& Facets

$\begin{array}{lllll}\text { Variables } & \text { R-Square } & \text { F } & \text { Beta } & \text { Significance } \\ \text { Age } & 10 & 11.23 & .32 & .001 \\ \text { Warmth } & 20 & 15.39 & .36 & .000 \\ \text { Self- } & 26 & 11.5 & .25 & .005 \\ \text { Discipline } & 26 & & \end{array}$

Stepwise multiple regression was conducted utilizing the 30 facet scales of the NEO-PI-R. Two facet scales emerged as significant predictors of OCB - warmth, a facet of extraversion, and self-discipline, a facet of conscientiousness.

Initially the demographic factors of age and sex were tested as predictors of OCB. Next, the facet scales of the NEO-PI-R were introduced and tested for incremental predictive power. Age of employee but not sex was a demographic predictor of OCB. Adding the NEO-PI-R facet scales of warmth and self-discipline, facets of extraversion and conscientiousness respectively, significantly improved the regression equation. The standardized beta coefficients were significant in both cases.

Table 3 presents the results of the analysis for student satisfaction.

\begin{tabular}{lcccc}
\hline & \multicolumn{3}{c}{ Table 3 } & \\
Multiple Regression Analysis Of Satisfaction \& Facets & \\
Variables & r-square & F & beta & Significance \\
Age & 05 & 5.03 & .23 & .02 \\
Self- conscious & 12 & 12.82 & -.35 & .001 \\
Achievement Striving & 20 & 11.5 & .31 & .001 \\
Openness to Values & 27 & 10.9 & .26 & .006 \\
\hline
\end{tabular}

The second analysis similarly examined student satisfaction. First the demographic factors of age and sex were tested as predictors of satisfaction. Next, the facet scales of the NEO-PI-R were introduced and tested for incremental predictive power. Similar to OCB, age of employee but not sex was a demographic predictor of student satisfaction. Adding the NEO-PI-R facet scales resulted in a significant equation with self consciousness (inversely related), achievement striving, and openness to values; facets of neuroticism, conscientiousness, and openness to experience respectively.

\section{Discussion}

This study had two major goals. The first was to examine the role of personality in organizational citizenship behavior. The second was to extend the findings of the OCB literature to the academic experience and to student satisfaction.

This study demonstrated the advantage of using facets of the 5 broad personality dimensions to elucidate the relationship between personality and OCB and student satisfaction. Both correlational analysis and regression 
analysis demonstrated that differential traits were associated with OCB and student satisfaction despite the fact that these two variables were highly correlated with one another.

In terms of OCB self-discipline, a facet of conscientiousness, and warmth, a facet of extraversion, added significant predictive power to the obtained regression equation. These findings further make intuitive sense as the former trait is consistent with individuals who are capable of motivating themselves to complete tasks. It is not much of a stretch that these same individuals would be able to motivate others through the use of OCB's.

The second trait, warmth, is extremely consistent with LePine et al.'s (2002) characterization of OCB as comprising cooperativeness. Warm individuals are genuinely friendly and affectionate and thus would seem to epitomize people likely to engage in OCB's. It is noteworthy, as well, that this facet is said to be very close to agreeableness.

In terms of student satisfaction, three different facet scales significantly add to the predictive power of the demographic regression equation. The lack of self-conscientiousness, achievement striving, and openness to values; facets of neuroticism, conscientiousness, and openness to experience respectively; formed the elements of the regression equation.

That lack of self-conscientiousness should be related to student satisfaction is somewhat anomalous though it may reflect the fact that school being a social situation may make self-conscious people uncomfortable and thus less satisfying. The trait of openness to values and its relationship to student satisfaction may be interpreted as indicating that individuals who are more questioning of the values that they were given as children may derive more satisfaction at university than individual who are less open to new ideas. It is noted that both these interpretations suggest that the personality traits in question are quite specific to the academic situation and probably would not be replicated in a work situation.

Achievement striving, too, may also be related to the academic setting because of the constant feedback that the classroom provides students, i.e., students with high achievement needs are probably quite at home at school. Though a case could be made that this trait is more likely to be generalizable to the work setting, it is likely that all three personality components of student satisfaction are highly specific to the academic environment.

Finally, it appears that the concept of OCB is generalizable to the academic setting. Future research should concentrate on studying freshman students to determine the extent to which OCB at school translate into retention figures.

\section{References}

1. Bateman, T.S, \& Organ, D.W. (1983). "Job satisfaction and the good soldier: The relationship between affect and employee "citizenship'". Academy of Management Journal, 26, 587-595.

2. Borman, W.C., \& Motowildo, S.J. (1993). "Expanding the criterion domain to include elements of contextural performance”. In N. Schmitt \& W. C. Borman (Eds.) Personnel selection in organizations (pp. 71-98). San Francisco: Jossey-Bass.

3. Borman, W.C., \& Motowildo, S.J. (1997). "Task performance and contextual performance: The meaning for personnel selection research". Human Performance, 10, 99-109.

4. Brief, A.P., \& Motowildo, S.J. (1986). "Prosocial organizational behaviors". Academy of Management Review, 11, 710-725.

5. Coleman, V.I., \& Borman, W.C. (2000). "Investigating the underlying structure of the citizenship performance domain". Human Resource Management Review, 10, 25-44.

6. Costa, P.T., \& McCrae, R.R. (1992). NEO-PI-R Professional manual. Odessa, FL: Psychological Assessment Resources Inc.

7. George, J.M., \& Jones, G.R. (1997). “Organizational spontaneity in context”. Human Performance, 10, 153-170. 
8. Ilgen, D.R., \& Puloakos, E.D. (1999). "The changing nature of performance: implications for staffing, motivation, and development". San Francisco: Josey-Bass.

9. LePine, J.A., Erez, A., Johnson, D.E. (2002). "The nature and dimensionality of organizational citizenship behavior: A critical review and meta-analysis". Journal of Applied Psychology, 87, 52-65.

10. McCrae, R.R., \& Costa, P.T. (1987). "Validation of the five-factor model of personality across instruments and observers".

11. Morrison, E.W. (1994). "Role definitions and organizational citizenship behavior: The importance of the employee's perspective". Academy of Management Journal, 37, 1543-1567.

12. Motowildo, S.J., \& Schmidt, M.J. (1999). "Performance assessment in unique jobs". In D.R. Ilgen \& E.D. Pulakos (Eds.) The changing nature of performance: implications for staffing, motivation, and development. San Francisco: Josey-Bass.

13. Neuman, G.A., \& Kickul, J.R. (1998) "Organizational citizenship behaviors: Achievement orientation and personality". Journal of Business and Psychology, 13, 263-279.

14. Organ, D.W. (1988). Organizational citizenship behavior: The good soldier syndrome. Lexington, MA: Lexington Books.

15. Organ, D.W. (1997). "Organizational citizenship behavior: It's construct clean-up time”. Human Performance, 10, 85-97.

16. Organ, D.W. \& Lingl, A. (1995). "Personality, satisfaction, and organizational citizenship behavior". Journal of Social Psychology, 135, 339-350.

17. Organ, D.W. \& Ryan, K. (1995). "A meta-analytic review of attitudinal and dispositional predictors of organizational citizenship behavior”. Personnel Psychology, 48, 776-801.

18. Paunonen, S.V., \& Ashton, M.C. (2001). "Big five factors and facets and the prediction of behavior". Journal of Personality and Social Psychology, 81, 524-539.

19. Podsakoff,P.M., MacKenzie, S.B., Moorman, R.H., \& Fetter, R.(1990). "Transformational leader behaviors and their effects on follower's trust in leader, satisfaction, and organizational citizenship behavior". Leadership Quarterly, 1, 107-142.

20. Podsakoff,P.M., MacKenzie, S.B., Paine, J.B., \& Bacharach, D.G. (2000). “Organizational citizenship behaviors: A critical review of the theoretical and empirical literature and suggestions for future research". Journal of Management, 26, 513-563.

21. Smith, C. A., Organ, D.W., \& Near, J.P. (1983). "Organizational citizenship behavior: Its mature and antecedents". Journal of Applied Psychology, 68, 653-663.

22. VanDyne, L., Cummings, L.L., \& McleanParks, J.M. (1995). "Extra-role behaviors: In pursuit of construct and definitional clarity (A bridge over muddied waters)". In L.L. Cummings \& B.M. Staw (Eds.) Research in organizational behavior (Vol. 17, pp. 215-285). Greenwich, CT:JAI press.

23. VanDyne, L., Graham, J.G., \& Dienesch, R.M. (1994). "Organizational citizenship behavior: Construct redefinition, operationalization, and validation". Academy of Management Journal, 37, 765-802.

24. Williams, L.J., \& Anderson, S.E. (1991). "Job satisfaction and organizational commitment as predictors of organizational citizenship and in-role behaviors". Journal of Management, 17, 601-617. 
Notes 